\title{
Abemaciclib, a Recent Novel FDA-Approved Small Molecule Inhibiting Cyclin-Dependant Kinase 4/6 for the Treatment of Metastatic Breast Cancer: A Mini-Review
}

\author{
Lou Anna Voli1,2, Janat A. Mamyrbékova², Jean-Pierre Bazureau1 ${ }^{*}$ \\ ${ }^{1}$ Institut des Sciences Chimiques de Rennes ISCR, UMR CNRS 6226, Université de Rennes 1, Campus de Beaulieu, Campus de \\ Beaulieu, Bât. 10A, CS 74205, 263 Avenue du Général Leclerc, 35042 Rennes Cedex, France \\ ${ }^{2}$ Laboratoire de Chimie Bio-Organique et de Subtances Naturelles (LCBOSN), Université Nangui Abrogoua, Voie Express \\ d'Abobo Adjamé, Abidjan, Côte d'Ivoire \\ Email: lou-anna.voli@univ-rennesl.fr, *jean-pierre.bazureau@univ-rennes1.fr, kojanova1926@hotmail.fr
}

How to cite this paper: Voli, L.A., Mamyrbékova, J.A. and Bazureau, J.-P. (2020) Abemaciclib, a Recent Novel FDA-Approved Small Molecule Inhibiting Cyclin-Dependant Kinase $4 / 6$ for the Treatment of Metastatic Breast Cancer: A Mini-Review. Open Journal of Medicinal Chemistry, 10, 128-138.

https://doi.org/10.4236/ojmc.2020.103007

Received: June 25, 2020

Accepted: August 29, 2020

Published: September 2, 2020

Copyright $\odot 2020$ by author(s) and Scientific Research Publishing Inc. This work is licensed under the Creative Commons Attribution International License (CC BY 4.0).

http://creativecommons.org/licenses/by/4.0/

\begin{abstract}
Abemaciclib (Verzerio ${ }^{\circledR}$ ) is a cell cycle inhibitor of both CDK4 and CDK6. In 2017, abemaciclib was approved by the Food and Drug Administration (FDA) and, in 2018 by the European Medicines Agency (EMA) for the treatment of postmenopausal women with hormone receptor positive $\left(\mathrm{HR}^{+}\right)$, human epidermal growth factor receptor 2 negative (HER2 ${ }^{-}$) advanced breast cancer. In this mini-review, we provide a series of information for respectively their targets and its selectivity, results on preclinical trial, clinical phase I, II and III trials, and some perspectives. We also describe the batch and flow steps used for the synthesis of this cancer drug.
\end{abstract}

\section{Keywords}

Approved Drug, Abemaciclib, FDA, EMA, CDK4/6, Protein Kinase Inhibitor, Metastatic Breast Cancer

\section{Introduction}

Imatinib (1) (Figure 1; Gleevec ${ }^{\circledR}$ from Novartis, Basel, Switzerland) was the first approved protein kinase inhibitor [1] [2] in May 2001 by the Food and Drug Administration for the treatment of myeloid leukemia [3]. To date, the number of protein kinase inhibitors (PKIs) approved worldwide continues to grow steadily from 2001 to January 2018 period: 39 drugs have been approved [4] by Food 
and Drug Administration, Chinese and European regulatory authorities for their respective markets.

In 2017, Food and Drug Administration approved the palbociclib (2) [5], a first-in-class inhibitor of CDK4/6 [6] developed by Pfizer for the treatment of postmenopausal women with hormone-receptor positive, HER-2 negative advanced breast cancer after initial endocrine-based therapy. During the Phase 2 PALOMA-1/TRIO 18 study, treatment with palbociclib (2) was associated to letrozole [7]. During the same period, ribociclib (3) owned by Novartis, the US Food and Drug Administration and the European Medicines Agency, also approved a direct competitor of palbociclib (2), in March 2017 for the treatment of metastatic breast cancer [8] [9].

Now the purpose of this mini-review is to provide information's on the third CDK4/6 inhibitor approved by Food and Drug Administration in 2017 named as abemaciclib (4) (LY2835219), for the treatment of certain breast cancer [10] [11].

\section{Abemaciclib}

\subsection{Names and Structure}

Abemaciclib (4) (Figure 2) is the active ingredient of Verzerio ${ }^{\circledR}$, commercialized by Eli Lilly and Co. Its IUPAC name is: $N$-[5-[(4-ethylpiperazin-1-yl)methyl]pyridin-2-yl]- $N$ '-[5-fluoro-4-(7-fluoro-2-methyl-3-methylethyl-3 $H$-benzimidazol5-yl)-pyrimidin-2-yl]-amine. CAS: 1231929-97-7.

\subsection{Uses}

Abemaciclib (4) was designated as a breakthrough therapy for metastatic breast cancer after successful Phase I [12], and Phase II [13] trials realized respectively<smiles>Cc1ccc(NC(=O)c2ccc(CN3CCN(C)CC3)cc2)cc1Nc1nccc(-c2cccnc2)n1</smiles>

Imatinib (1)<smiles>CC(=O)c1c(C)c2cnc(Nc3ccc(N4CCNCC4)cn3)nc2n(C2CCCC2)c1=O</smiles>

Palbociclib (2)<smiles>CN(C)C(=O)c1cc2cnc(Nc3ccc(N4CCNCC4)cn3)nc2n1C1CCCC1</smiles>

Ribociclib (3)

Figure 1. Chemical structure of Imatinib (1) and, the CDK4/6 inhibitor drugs palbociclib (2) and ribociclib (3).<smiles>CCN1CCN(Cc2ccc(Nc3ncc(F)c(-c4cc(F)c5nc(C)n(C(C)C)c5c4)n3)nc2)CC1</smiles>

Abemaciclib (4)

Figure 2. Abemaciclib chemical structure (4). 
in May and December 2014. Food and Drug Administration approved it for use in the USA in September 2017 [14] and the European Medicines Agency regulatory authorities in September 2018.

\subsection{Targets and Selectivity}

For regulating the cell cycle, the G1 restriction point is critical and is controlled by the retinoblastoma $(\mathrm{Rb})$ pathway (CDK4/6-cyclin D1-Rb-p16/ink4a). The retinoblastoma protein is a tumor suppressor, which inhibits proliferation through binding to and suppressing the activity of the E2F family of transcription factors. The central role of the Rb pathway for controlling cellular proliferation has been demonstrated by its dysregulation in human cancer. Transition through the restriction point requires phosphorylation of $\mathrm{Rb}$ by $\mathrm{CDK} 4 / 6$, which validated cancer drug targets [15].

Eli Lilly and Company identified the 2-anilino-2,4-pyrimidine-[5-benzimidazole] scaffold as potent inhibitors of CDK4/cyclin D1 and CDK6/cyclin D1 by compound screening. Optimization of the scaffold has been realized by structure-activity relationship (SAR) studies associated to computing structure-based design and biochemical screening against a small panel of kinases to improve potency and selectivity, and with a colo-205-cell high content imaging monitoring inhibition of its phosphorylation. Compounds with good physicochemical and pharmacokinetic properties were then evaluated for in vivo tumor activity against xenograft tumors in immunodeficient mice. In this context, LY2835219 emerged as a good candidate for its potential biological activities and optimal pharmacological properties. In biochemical assays (Table 1), abemaciclib (4) (or LY2835219) inhibited respectively CDK4/cyclin D1 and CDK6/cyclin D1 with $\mathrm{IC}_{50}$ $2 \mathrm{nM}$ and $9.9 \mathrm{nM} . \mathrm{K}_{\mathrm{i}}$ ATP constants were also determined through kinetic studies; for CDK4/cyclin D1, it showed $\mathrm{K}_{\mathrm{i}} \mathrm{ATP}=0.6 \mathrm{nmol} / \mathrm{l}$ and $2.4 \mathrm{nmol} / \mathrm{l}$ for CDK6/ cyclin D1. This means that abemaciclib (4) is a competitive ATP inhibitor [16].

Table 1. Abemaciclib (4) (LY2835219) biochemical profiling (issued from [17]).

\begin{tabular}{ccc}
\hline Biochemical profiling $^{a}$ & $\mathrm{IC}_{50}(\mathrm{nmol} / \mathrm{l})^{b}$ & $\mathrm{~K}_{\mathrm{i}}[\mathrm{ATP}](\mathrm{nmol} /)^{b}$ \\
\hline CDK4/cyclin D1 & $2.0 \pm 0.4(n=5)$ & $0.6 \pm 0.3(n=2)$ \\
CDK6/cyclin D1 & $9.9(\mathrm{n}=1)$ & $-4 \pm 1.2(n=2)$ \\
CDK1/cyclin B1 & $1627 \pm 666(n=5)$ & - \\
CDK2/cyclin E & $504 \pm 298(n=3)$ & - \\
CDK9/cyclin T1 & $57 \pm 42(n=4)$ & - \\
CDK7/Mat1/cyclin H1 & $3910 \pm 2410(n=4)$ & - \\
PIM1 & $50(n=1)$ & - \\
PIM2 & $3400(n=1)$ & - \\
ERK1 & $>20,000(n=1)$ & - \\
\hline
\end{tabular}

aunless otherwise indicated, all data was generated internally at Eli Lilly and Co. All human kinases. ${ }^{b}$ for $\mathrm{n}<$ 1 , average of independent determinations \pm standard deviation. 
On the other hand, in measured $\mathrm{IC}_{50}$ for biochemical kinase selectivity against CDK1/cyclin B1, CDK2/cyclin E and CDK7/Mat1/cyclin H1, abemaciclib (4) showed a gain 2 - 3 orders of magnitude. Against PIM1, an activity was also seen $\left(\mathrm{IC}_{50} 50 \mathrm{nM}\right)$ and a lesser extent activity against PIM2 ( $\left.\mathrm{IC}_{50} 3.4 \mu \mathrm{M}\right)$ (Table 1$)$.

\subsection{Preclinical and Clinical Trials}

In preclinical development [17], pharmacokinetic and pharmacodynamic properties of methane sulfonate salt of abemaciclib (4) (or LY2835219) were assessed in mice bearing colo-205-human xenografts $24 \mathrm{~h}$ after oral dosing for the observation of cell cycle effects. It significantly inhibited the growth of colo-205-xenografts with no loss of body weight or other signs of toxicity during or after treatment (dose up to $100 \mathrm{mg} / \mathrm{kg}$ ) (Figure 3(a)). The long-term safety and antitumor activity of abemaciclib (4) (LY2535219) was also explored. Treatment of colo-205-xenograft bearing mice during 56 days with continuous and intermittent dosing schedules produced a similar efficient inhibition without loss of body weight (Figure 3(b)).

In Phase I trial [18], effect of abemaciclib (4) has been explored in five different types $(n=132)$ with a cohort of 47 patients (median age: 55 years) with metastatic breast cancer who received a median of 7 prior-therapeutics. In the cohort of 47 patients, $74 \%$ had visceral metastases and $76 \%$ (36 patients) were hormone receptor-positive $\left(\mathrm{HER}^{+}\right)$. Among this $\mathrm{HER}^{+}$patient's group, 25\% (9 patients) had confirmed partial responses and 56\% (20 patients) had stable disease (including 2 patients with unconfirmed responses). The clinical benefit rate was $61 \%$ and disease central rate was $81 \%$. The maximum tolerated dose was 200 mg every 12 hours (fatigue was the dose-limiting toxicity).
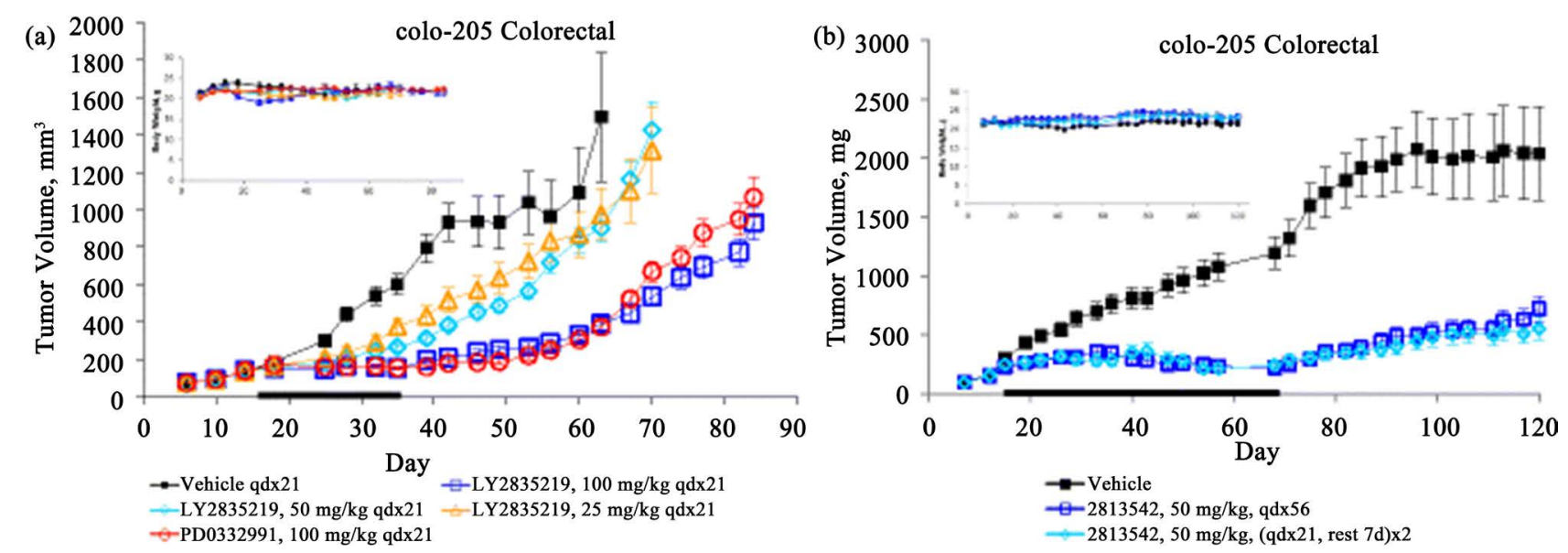

Figure 3. In vivo antitumor activity of abemaciclib (4) (LY2835219) in subcutaneous human xenografts [13]. Tumor have been implanted in the rear flank of athymic mice and randomized for treatment when the tumor volume reached 150 to $200 \mathrm{~nm}^{3}$. LY2835219 and PD0332991 (or palbociclib isethionate CAS 827022-33-3) were administered at the indicated dose and schedule. Treatment period is indicated by the horizontal black bar along the X-axis, body weight shown for each experiment is shown in the upper left corner. (a) (left) Effect of 25, 50 or $100 \mathrm{mg} / \mathrm{kg}$ of LY2835219 and $100 \mathrm{mg} / \mathrm{kg}$ of PD0332991 on colo-205-xenografts. (b) (right) LY2835219 inhibits tumor growth and it is well tolerated in mice bearing colo-205-xenografts when dosed 56 days with $50 \mathrm{mg} / \mathrm{kg}$ continuously or intermittently. 
The MONARCH 2 clinical Phase III study (Clinical Trials.gov: NTC 02107703) of women with $\mathrm{HER}^{+}$and human epidermal growth factor-receptor 2-negative ABC was realized between August 2014 and December 2015 with 669 patients [19]. This Phase III, randomized, double-blind, placebo-controlled study of fulvestrant with abemaciclib (4) $(n=446)$ or without $(n=223)$ was conducted in 142 centers and in 19 countries. Treatment of patients randomly assigned 2:1 to receive abemaciclib (4) or placebo (150 mg twice daily) on a continuous schedule and fulvestrant (500 mg, per label), improved significantly the progression-free survival (PFS) versus fulvestrant alone (median, $16.4 \mathrm{v} 9.3$ months, hazard ratio, $0.553 ; 95 \% \mathrm{Cl}, 0.449$ to $0.681 ; \mathrm{P}<0.001)$. During treatment, the common adverse events in the abemaciclib (4) versus placebo arms were: diarrhea $(86.4 \% \mathrm{v} 24.7 \%)$, neutropenia $(46 \% \mathrm{v} 4.0 \%)$, nausea $(45.1 \% \mathrm{v}$ $22.9 \%)$ and fatigue (39.9\% v 26.9\%).

During MONARCH 3 Clinical Phase III [20] conducted between November 18, 2014 and November 11, 2015 with 493 women patients $\left(\mathrm{HR}^{+}\right.$and $\mathrm{HER}^{+}$advanced breast cancers) in 158 sites and in 22 countries, abemaciclib (4) dosed in combination with a nonsteroidal A1 (anastrazole or letrozole) improved progression-free survival and the clinical benefit rate $(79.4 \% \mathrm{v} 69.2 \%$ with placebo plus nonsteroidal A1).

In MONARCH 3 Final PFS (Progression Free Survival) study [21], a total of 125 women patients $(38.1 \%)$ in the abemaciclib arm and 35 patients $(21.2 \%)$ in the placebo arm remained in treatment. Following 24 cycles of treatments, the mean decrease in tumor size was $76.1 \%$ in the abemaciclib arm and $50 \%$ in the placebo arm. For patients responded to abemaciclib (4), the response typically occurred within the first 8 months of treatment (Figure 4(a)) Results of this clinical Phase III trial come in light for CD4/6 cyclin D in the regulation of cancer immune surveillance [22] [23].

\subsection{Syntheses}

As depicted in the retrosynthetic approach (Figure 5), abemaciclib (4) [24]

(a)

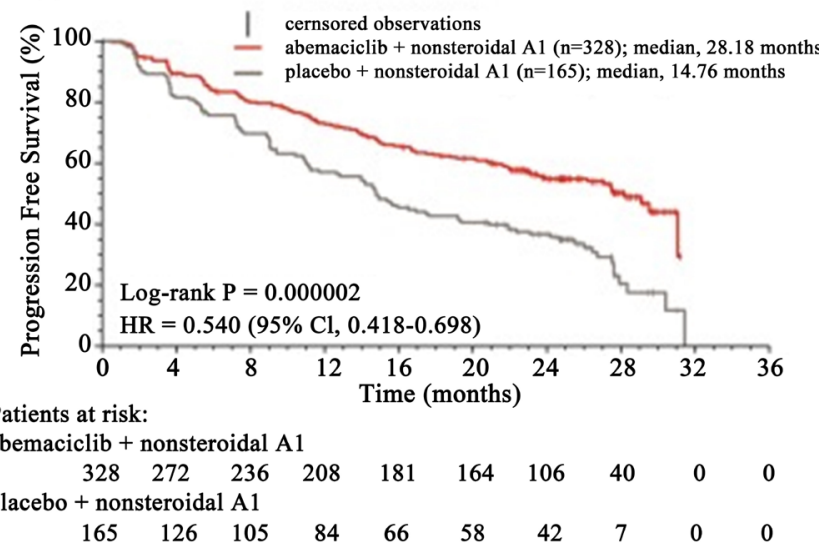

(b)

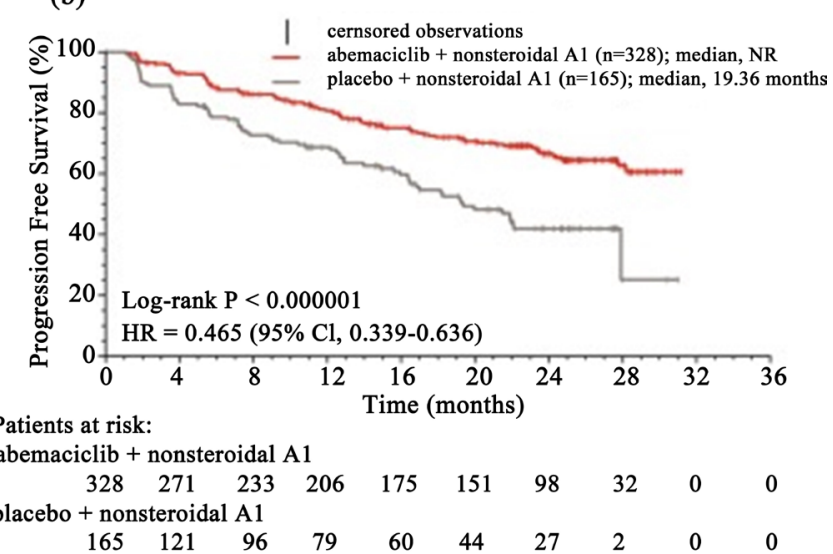

Figure 4. Progression-free survival. (a) (left) Investigator-assessed and (b) (right) Independent central review in the intent-to-treat population. NR, not reached [20]. 
involved a carbon-carbon Suzuki coupling as key step between boronic ester (5) and 2,4-dichloro-5-fluoro pyrimidine (6) as readily available commercial building blocks [25]. For this, the authors used $\mathrm{PdCl}_{2}\left(\mathrm{PPh}_{3}\right)_{2}$ with $\mathrm{Na}_{2} \mathrm{CO}_{3}$ in DME at $80^{\circ} \mathrm{C}$ and they obtained the biaryl compound (9) after $4 \mathrm{~h}$ in $66 \%$ isolated yield (Scheme 1).

For the second step, they investigated a carbon-nitrogen coupling via Buchwarld-Hartwing amidation. For optimization of this N,C-coupling, they explored successively the choice of appropriate solvent $(\mathrm{MeOH}, \mathrm{EtOH}, \mathrm{t}-\mathrm{AmylOH})$ due to solubility limitations of the starting reagents (9) and (7), the ligand and reaction temperature. Using the more hindered $t$-AmylOH (no undesired $t$-Amyl ether by-product was observed), DPEPhos (as sufficient active catalyst), they obtained successful carbon-nitrogen coupling after $18 \mathrm{~h}$ at $100^{\circ} \mathrm{C}$ and the aldehyde intermediate (10) was prepared quantitatively.

The third and last step in the synthesis of abemaciclib (4) is a classical reductive amination involving the aldehyde (10) and $\mathrm{N}$-ethylpiperazine (8). After a few set of explorating experiences with $\mathrm{NaBH}(\mathrm{OAc})_{3}$ as reductant, they observed a 97:3 distribution of (4) and reduced aldehyde (10) which, increased difficulties of separation and purification through crystallization. In this context, they dropped out these classical reductive reaction conditions and these setbacks led to the exploration of Leuckart-Wallach conditions without catalyst. Starting from 4 equivalents of formic acid as source of reducing reagent associated to trimethyl orthoester for removal of water, reductive amination of aldehyde (10) in the presence of 2 equivalents of $N$-ethylpiperazine afforded quantitatively after $16 \mathrm{~h}$ abemaciclib (4) in $74 \%$ isolated yield.

The authors continued to develop efforts on Leuckart-Wallach reductive amination conditions for a robust batch process and a more convergent approach<smiles>CCN1CCNCC1</smiles>

Figure 5. Retrosynthetic strategy for the preparation of abemaciclib (4) [25].<smiles>Cc1nc2c(F)cc(B3OC(C)(C)C(C)(C)O3)cc2n1C(C)C</smiles>

5

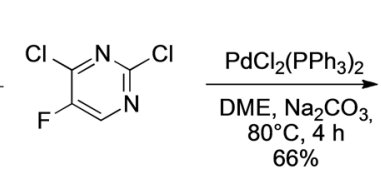

6<smiles>Cc1ncc(F)c(-c2cc(F)c3nc(C)n(C(C)C)c3c2)n1</smiles>

9

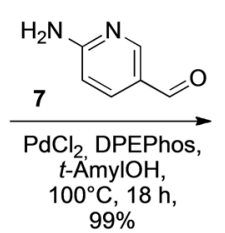
$99 \%$<smiles>Cc1nc2c(F)cc(-c3nc(Nc4ccc(C=O)cn4)ncc3F)cc2n1C(C)C</smiles>

10

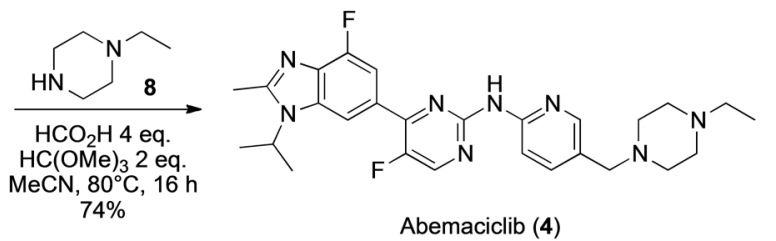

Scheme 1. Initial route used for the three-step synthesis of abemaciclib (4). 


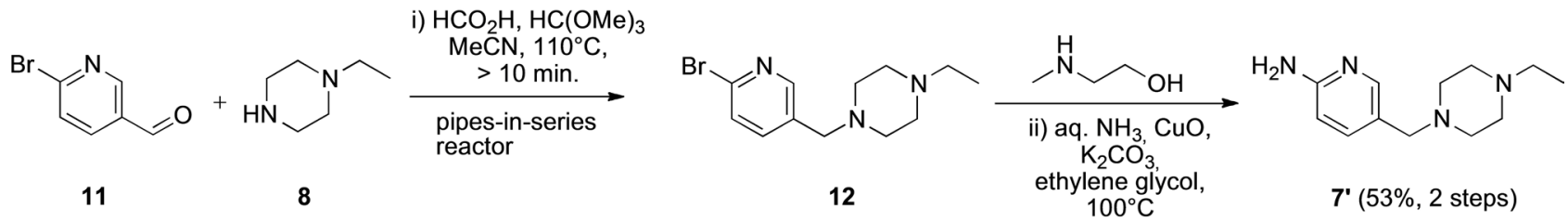

Scheme 2. Process for preparation of 2-amino pyridine (7’) used for carbon-nitrogen coupling of Buchwarld-Hartwing with the biaryl compound (9) [26].

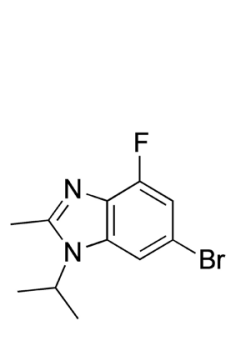

13 for the kilogram scale preparation of abemaciclib (4) [26]. Briefly, they opted for modifications on the 6-aminopyridine-3-carbaldehyde (7) used in the carbonnitrogen coupling of Buchwarld-Hartwing amidation.

In fact, a robust process (Scheme 2) was fully realized to make directly the 2-amino pyridine ( $\left.7^{\prime}\right)$ through two telescoped steps: i) the first was the LeuckartWallach reductive amination using pipe-in-series reactors with near instantaneous heat-up times to maximize conversion and to reduce by-products, ii) and the second was an Ullmann coupling with aqueous ammonia. Fortunately, the use of 2-methylaminoethanol at $100^{\circ} \mathrm{C}$ provided high conversion (99\%).

For the intermediate (9) issued from the carbon-carbon Suzuki coupling (Scheme 1), the Eli Lilly's chemists, finally, developed also a telescoped Miyaura borylation and Suzuki coupling (Scheme 3) to maintain its high quality [27].

The use of bis(pinacolato)diboron (BisPin) and the aid of a Quality by Design (QbD) approach was the key point of success to control the risk of pinacol precipitation in THF and to provide a maximally flexible process for manufacturing in large scale.

\subsection{Perspectives}

Abemaciclib pharmacological profile as novel CDK4/6 inhibitor represented an optimal first line treatment for hormone receptor (HR) positive, human epidermal growth-factor receptor 2 (HER2) non-amplified metastatic breast cancer (MBC) in combination with endocrine therapy. Its indication can be extended for treatments of patients (clinical phase II) with brain metastases secondary to $\mathrm{ER}^{+}$breast cancer, non-small lung cancer, or melanoma (Clinical Trials.gov: NTC 02308020). Given the observed benefits of CDK4/6 inhibitors in combination with endocrine therapy for patients with $\mathrm{HR}^{+}$, HER2-non amplified MBC,

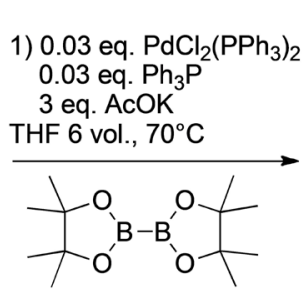

1.4 eq. BisPin

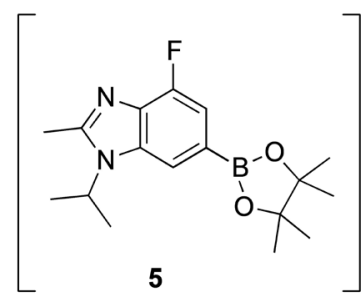

5
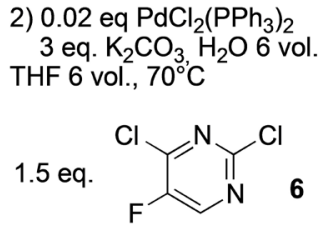

3) add $\mathrm{THF} / \mathrm{H}_{2} \mathrm{O}$ to dissolve product and inorganic solids

4) separate aqueous phase

5) 70 to $0^{\circ} \mathrm{C}$ (cryst.)

6) THF wash / dry

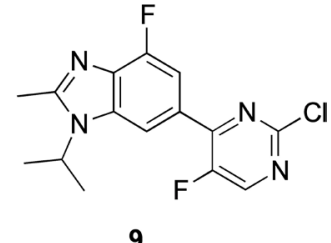

9

Scheme 3. Telescoped Borylation Suzuki coupling for the preparation of intermediate (9) [26]. 
adjuvant studies are now underway to investigate the combination in $\mathrm{HR}^{+}$, HER2-non amplified early breast cancer [28].

\section{Conclusion}

For the treatment of advanced or metastatic $\mathrm{HR}^{+}$breast cancer, $\mathrm{CDK} 4 / 6$ inhibitors are an effective option. Their oral administration and their toxicity profile [29] are convenient and manageable. In this context, abemaciclib appears to possess unique pharmacological properties and seems to obtain the best results heavily pretreated with visceral disease and worse prognosis. The approval of abemaciclib by Food and Drug Administration adds another option to the armamentarium of effective CDK4/6 inhibitors [30] [31] currently available.

\section{Author Contributions}

The three authors contributed equally to this manuscript.

\section{Funding}

This research received no external funding.

\section{Acknowledgements}

One of us (L-A.V.) wishes to thank the "Ministère de l'Enseignement Supérieur et de la Recherche de la République de Côte d'Ivoire" for the grants. Thanks to the "Marine Molecules, Metabolism and Cancer Network" of the "Cancéropole Grand Ouest" and the "Ligue Contre le Cancer CD 35" for financial support of the current contracts.

\section{Conflicts of Interest}

The authors declare no conflicts of interest regarding the publication of this paper.

\section{References}

[1] Chonga, Q.-Y., Koka, Z.-H., Bui, N.-L.-C., Xiang, X., Wong, A.L.-A., Yong, W.-P., Sethi, G., Lobie, P.E., Wang, L.W. and Goh, B.-C. (2020) A Unique CDK4/6 Inhibitor: Current and Future Therapeutic Strategies of Abemaciclib. Pharmacological Research, 156, Article ID: 104686. https://doi.org/10.1016/j.phrs.2020.104686

[2] Wu, P., Nielsen, T.E. and Clausen, M.H. (2015) FDA-Approved Small-Molecules Kinases Inhibitors. Trends in Pharmacological Sciences, 36, 422-439. https://doi.org/10.1016/j.tips.2015.04.005

[3] CenterWatch. 2001 FDA Approved Drugs. https://www.centerwatch.com/drug-information/fda-approved-drugs/year/2001

[4] Carles, F., Bourg, S., Meyer, C. and Bonnet, P. (2018) PKIDB: A Curated, Annotated and Updated Database of Protein Kinases in Clinical Trials. Molecules, 23, 908-926. https://doi.org/10.3390/molecules23040908

[5] FDA Approves Palbociclib for Metastatic Breast Cancer. http://www.onclive.com/web-exclusives/FDA-Approves-Palbociclib-for-Metastatic- 
Breast-Cancer

[6] Lu, J. (2015) Palbociclib: A First-in-Class CDK4/CDK6 Inhibitor for the Treatment of Hormone-Receptor Positive Advanced Breast Cancer. Journal of Hematology \& Oncology, 8, 98-100. https://doi.org/10.1186/s13045-015-0194-5

[7] Finn, R.S., Crown, J-P., Lang, I., Boer, K., Bondarenko, I.M., Kulyk, S.O., Ettl, J., Patel, R., Pinter, T., Schmidt, M., Shparyk, Y., Thummala, A.R., Voytko, N.L., Fowst, C., Huang, X., Kim, S.T., Randolph, S. and Slamon, D.J. (2015) The Cyclin-Dependent Kinase 4/6 Inhibitor Palbociclib in Combination with Letrozole versus Letrozole Alone as First-Line Treatment of Oestrogen Receptor-Positive, HER2-Negative, Advanced Breast Cancer (PALOMA-1/TRIO-18): A Randomised Phase 2 Study. The Lancet Oncology, 16, 25-35.

https://doi.org/10.1016/S1470-2045(14)71159-3

[8] Porati, M. and Marzaro, G. (2019) Third-Generation CDK Inhibitors: A Review on the Synthesis and Binding Modes of Palbociclib, Ribociclib and Abemaciclib. European Journal of Medicinal Chemistry, 172, 149-153.

https://doi.org/10.1016/j.ejmech.2019.03.064

[9] Study of Efficacy and Safety of LEE011 in Postmenopausal Women with Advanced Breast Cancer (MONALEESA-2). ClinicalTrials.gov. Clinical Trial Number NCT01958021. https://www.clinicaltrials.gov/show/NCT01958021

[10] Abemaciclib Receives FDA Approval for Certain Metatstatic Breast Cancers. http://www.oncotherapynetwork.com/breast-cancer-targets/abemaciclib-receives-fd a-approval-certain-metastatic-breast-cancers

[11] Hurvitz, S.A., Martin, M., Press, M.F., Chan, D., Fernandez-Abad, M., Petru, E., Rostorfer, R., Guarneri, V., Huang, C-S., Wijayawardana, B.S.S., Brahmachary, M., Ebert, P.J., Hossain, A., Liu, J., Abel, A., Aggarwal, A., Jansen, V.M. and Slamon, D.J. (2020) Potent Cell-Cycle Inhibition and Upregulation of Immune Response with Abemaciclib and Anastrozole in neoMONARCH, Phase II Neoadjuvant Study in HRp/HER2 Breast Cancer. Clinical Cancer Research, 26, 566-580. https://doi.org/10.1158/1078-0432.CCR-19-1425

[12] Shapiro, G., Rosen, L.S., Tolcher, A.W., Goldman, J.W., Gandhi, L., Papadopoulos, K.P., Tolaney, S.M., Beeram, M., Rasco, D.W., Kulanthaivel, P., Li, Q., Hu, T., Cronier, D., Chan, E.M., Flaherty, K., Wen, P.Y. and Patnaik, A. (2013) A First-in-Human Phase I Study of the CDK4/6 Inhibitor, LY2835219, for Patients with Advanced Cancer. Journal of Clinical Oncology, 31, 2500.

https://doi.org/10.1200/jco.2013.31.15_suppl.2500

[13] Clinical Activity of Abemaciclib (LY2835219), a Cell Cycle Inhibitor Selective for CDK4 and CDK6, in Patients with Relapsed or Refractory Mantle Cell Lymphoma. https://ash.confex.com/ash/2014/webprogram/Paper72259.html

[14] FDA's Breakthrough Therapy Designation to Abemaciclib for Breast Cancer. Oncology Times LWW Journals.

https://journals.lww.com/oncology-times/blog/fdaactionsandupdates/pages/post.as px?PostID $=119$

[15] Dickson, M.A. (2014) Molecular Pathways: CDK4 Inhibitors for Cancer Therapy. Clinical Cancer Research, 13, 3379-3383. https://doi.org/10.1158/1078-0432.CCR-13-1551

[16] Gelbert, L.M., Cai, S., Lin, X., Sanchez-Martinez, C., del Prado, M., Lallena, M.J., Torres, R., Ajamie, R.T., Wishart, G.N., Flack, R.S., Neubauer, B.L., Young, J., Chan, E.M., Iversen, P., Cronier, D., Kreklau, E. and de Dios, A. (2014) Preclinical Characterization of the CDK4/6 Inhibitor LY2835219: In-Vivo Cell Cycle-Dependent/Independent Anti-Tumor Activities Alone/In Combination with Gemcitabine. Investigational New Drugs, 32, 
825-837. https://doi.org/10.1007/s10637-014-0120-7

[17] Shapiro, G., Rosen, L.S., Tolcher, A.W., Goldman, J.W., Gandhi, L., Papadopoulos, K.P., Tolaney, S.M., Beeram, M., Rasco, D.W., Kulanthaivel, P., Li, Q., Hu, T., Cronier, D., Chan, E.M., Flaherty, K., Wen, P.Y. and Patnaik, A. (2014) Clinical Activity of LY2835219, a Novel Cell Cycle Inhibitor Selective for CDK4 and CDK6, in Patients with Metastatic Breast Cancer. AACR Annual Meeting 2014, San Diego, 5-9 April 2014, Abstract CT232.

[18] Sledge Jr., G.W., Toi, M., Neven, P., Sohn, J., Inoue, K., Pivot, X., Burdaeva, O., Okera, M., Masuda, N.A., Kaufman, P.A., Koh, H., Grischke, E.-M., Frenzel, M., Lin, Y., Barriga, S., Smith, I.C., Bourayou, N. and Antonio Llombart-Cussac, A. (2017) MONARCH 2: Abemaciclib in Combination with Fulvestrant in Women with $\mathrm{HR}^{+} / \mathrm{HER} 2^{-}$Advanced Breast Cancer Who Had Progressed While Receiving Endocrine Therapy. Journal of Clinical Oncology, 35, 2875-2884. https://doi.org/10.1200/JCO.2017.73.7585

[19] Goetz, M.P., Toi, M., Campone, M., Sohn, J., Paluch-Shimon, S., Huober, J., Park, I.H., Trédan, O., Chen, S.-C., Manso, L., Freedman, O.C., Jaliffe, G.G., Forrester, T., Frenzel, M., Barriga, S., Smith, I.C., Bourayou, N. and Di Leo, A. (2017) MONARCH 3: Abemaciclib as Initial Therapy for Advanced Breast Cancer. Journal of Clinical Oncology, 35, 3638-3646. https://doi.org/10.1200/JCO.2017.75.6155

[20] Johnston, S., Martin, M., Di Leo, A., Im, S.-A., Awada, A., Forrester, T., Frenzel, M., Hardebeck, M.C., Cox, J., Barriga, S., Toi, M., Iwata, H. and Goetz, M.P. (2019) MONARCH 3 Final PFS: A Randomized Study of Abemaciclib as Initial Therapy for Advanced Breast Cancer. Nature Breast Cancer, 5, Article No. 5. https://doi.org/10.1038/s41523-018-0097-Z

[21] O'Leary, B., Finn, R.S. and Turner, N.C. (2016) Treating Cancer with Selective CDK4/6 Inhibitors. Nature Reviews Clinical Oncology, 13, 417-430. https://doi.org/10.1038/nrclinonc.2016.26

[22] Lim, E., Beith, J., Frances Boyle, F., de Boer, R., Hui, R., Mc Carthy, N., Redfern, A., Wade, T. and Woodward, N. (2018) Emerging Data and Future Directions for CDK4/6 Inhibitor Treatment of Patients with Hormone Receptor Positive HER2-Non-Amplified Metastatic Breast Cancer. The Asia-Pacific Journal of Clinical Oncology, 14, 12-21. https://doi.org/10.1111/ajco.13065

[23] Coates, D.A., Gelbert, L.M., Knobeloch, J.M., De Dios Managa, A., De Prado Gonzalez, A., Filadelfa Del Prado Catalina, M., Garcia Parades, M.C., Martin de la Nava, M., Martin Ortega Finger, M.D., Martinez-Perez, J.A., Mateo Herranz, A.I., Perez Martinez, C. and Sanchez Martinez, C. (2010) Protein Kinase Inhibitors. US Patent 2010/0160340 A1.

[24] Frederick, M.O. and Kjell, D.P. (2015) A Synthesis of Abemaciclib Utilizing a Leuckart-Wallach Reaction. Tetrahedron Letters, 56, 949-951. https://doi.org/10.1016/j.tetlet.2014.12.082

[25] Frederick, M.O., Pietz, M.A., Kjell, D.P., Richey, R.N., Tharp, G.A., Touge, T., Yokoyama, N., Michio Kida, M. and Matsuo, T. (2017) Development of a Leuckart-Wallach Reaction in Flow for the Synthesis of Abemaciclib. Organic Process Research \& Development, 21, 1447-1451. https://doi.org/10.1021/acs.oprd.7b00234

[26] Merritt, J.M., Andiappan, M., Pietz, M.A., Richey, R.N., Sullivan, K.A. and Kjell, D.P. (2016) Mitigating the Risk of Coprecipitation of Pinacol during Isolation from Telescoped Miyaura Borylation and Suzuki Couplings Utilizing Boron Pinacol Esters: Use of Modeling for Process Design. Organic Process Research \& Development, 20, 178-188. https://doi.org/10.1021/acs.oprd.5b00324 
[27] Tolaney, S.M., Lin, N.U., Thornton, D., Klise, S., Costigan, T.M. and Turner, K. (2017) Abemaciclib for the Treatment of Brain Metastases (BM) Secondary to Hormone Receptor Positive $\left(\mathrm{HR}^{+}\right)$, HER2 Negative Breast Cancer. Journal of Clinical Oncology, 35, 1019-1019. https://doi.org/10.1200/JCO.2017.35.15_suppl.1019

[28] Martin, M., Hurvitz, S.A., Chan, D., Fernandez-Abad, M., Petru, E., Rostorfer, R., Guarneri, V., Huang, C.-S., Press, M.F., Costigan, T.M., Caldwell, C.W., Wijayawardana, S., Turner, P.K., Barriga, S. and Slamon, D.J. (2018) Abstract PD5-01: Final Results of NeoMONARCH: A Phase 2 Neoadjuvant Study of Abemaciclib in Post-Menopausal Women with Hormone Receptor Positive $\left(\mathrm{HR}^{+}\right)$, HER2 Negative Breast Cancer (BC). Cancer Research, 78, PD5-01.

https://doi.org/10.1158/1538-7445.SABCS17-PD5-01

[29] Martin, J.M. and Goldstein, L.J. (2018) Profile of Abemaciclib and Its Potential in the Treatment of Breast Cancer. OncoTargets and Therapy, 11, 5253-5259. https://doi.org/10.2147/OTT.S149245

[30] McCartney, A., Moretti, E., Sanna, G., Pestrin, M., Risi, E., Malorni, L., Biganzoli, L. and Di Leo, A. (2018) The Role of Abemaciclib in Treatment of Advanced Breast Cancer. Therapeutic Advances in Medical Oncology, 10, 1-14. https://doi.org/10.1177/1758835918776925

[31] Corona, S.P. and Generali, D. (2018) Abemaciclib: A CDK4/6 Inhibitor for the Treatment of $\mathrm{HR}^{+} / \mathrm{HeR} 2^{-}$Advanced Breast Cancer. Drug Design, Development and Therapy, 12, 321-330. https://doi.org/10.2147/DDDT.S137783 